\title{
Association between the body mass index and outcomes of patients resuscitated from out-of-hospital cardiac arrest: a prospective multicentre registry study
}

Heekyung Lee ${ }^{1}$, Jaehoon Oh ${ }^{1 *}$ (D), Hyunggoo Kang ${ }^{1}$, Tae Ho Lim', Byuk Sung Ko ${ }^{1}$, Hyuk Joong Choi ${ }^{1}$,

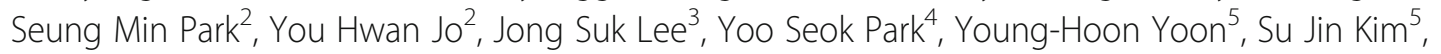
Young-Gi Min ${ }^{6}$ and for the Korean Cardiac Arrest Research Consortium (KoCARC) Investigators

\begin{abstract}
Background: The effects of the body mass index (BMI) on outcomes of patients resuscitated from cardiac arrest are controversial. Therefore, the current study investigated the association between the BMI and the favourable neurologic outcomes and survival to discharge of patients resuscitated from out-of-hospital cardiac arrest (OHCA).

Methods: This multicentre, prospective, nationwide OHCA registry-based study was conducted using data from the Korean Cardiac Arrest Resuscitation Consortium (KoCARC). We enrolled hospitals willing to collect patient height and weight and included patients who survived to the hospital between October 2015 and June 2018. The included patients were categorised into the underweight $\left(<18.5 \mathrm{~kg} / \mathrm{m}^{2}\right)$, normal weight $\left(\geq 18.5\right.$ to $\left.<25 \mathrm{~kg} / \mathrm{m}^{2}\right)$, overweight ( $\geq 25$ to $<30 \mathrm{~kg} / \mathrm{m}^{2}$ ), and obese groups $\left(\geq 30 \mathrm{~kg} / \mathrm{m}^{2}\right.$ ) according to the BMl per the World Health Organization (WHO) criteria. The primary outcome was a favourable neurologic outcome; the secondary outcome was survival to discharge. Univariate and multivariate analyses were performed to investigate the association between BMI and outcomes.

Results: Nine hospitals were enrolled; finally, 605 patients were included in our analysis and categorised per the WHO BMI classification. Favourable neurologic outcomes were less frequent in the underweight BMI group than in the other groups $(p=0.002)$; survival to discharge was not significantly different among the BMI groups $(p=0.110)$. However, the BMI classification was not associated with favourable neurologic outcomes or survival to discharge after adjustment in the multivariate model.
\end{abstract}

Conclusion: The BMI was not independently associated with favourable neurologic and survival outcomes of patients surviving from OHCA.

Keywords: Obesity, Body mass index, Out-of-hospital cardiac arrest

\footnotetext{
* Correspondence: ojjai@hanmail.net

1 Department of Emergency Medicine, College of Medicine, Hanyang

University, 222 Wangsimni-ro, Seongdong-gu, Seoul 04763, Republic of Korea

Full list of author information is available at the end of the article
}

C C The Author(s). 2021 Open Access This article is licensed under a Creative Commons Attribution 4.0 International License, which permits use, sharing, adaptation, distribution and reproduction in any medium or format, as long as you give appropriate credit to the original author(s) and the source, provide a link to the Creative Commons licence, and indicate if changes were made. The images or other third party material in this article are included in the article's Creative Commons licence, unless indicated otherwise in a credit line to the material. If material is not included in the article's Creative Commons licence and your intended use is not permitted by statutory regulation or exceeds the permitted use, you will need to obtain permission directly from the copyright holder. To view a copy of this licence, visit http://creativecommons.org/licenses/by/4.0/. The Creative Commons Public Domain Dedication waiver (http://creativecommons.org/publicdomain/zero/1.0/) applies to the data made available in this article, unless otherwise stated in a credit line to the data. 


\section{Introduction}

Overweight and obesity are defined as abnormal or excessive fat accumulation that may impair health. In 2016 , a total of $39 \%$ of adults aged $>18$ years were overweight, and $13 \%$ were obese [1]. The number of obese patients continues to be high worldwide, exceeding 30 to $40 \%$ in most sex and age groups in the United States [2]. The body mass index (BMI) is a simple weight-toheight ratio that is used to classify overweight and obese adult patients. A high BMI is associated with hypertension, type II diabetes mellitus, dyslipidaemia, and major cardiovascular diseases-such as heart failure, coronary heart disease, arrhythmia, and sudden cardiac arrestresulting in increased risks of both out-of-hospital cardiac arrest (OHCA) and in-hospital cardiac arrest (IHCA) [3-6].

A chest compression depth of $5-6 \mathrm{~cm}$ is recommended during cardiopulmonary resuscitation to ensure high-quality chest compressions. However, this chest compression depth is insufficient for obese patients who experience cardiac arrest because thorax changes and airway management-including bag-valve mask ventilation-are difficult in such patients considering the changes in their anatomy and distortions [7-11]. The survival and neurologic outcomes of obese patients or patients with a high BMI who experience cardiac arrest are lower than those of other patients [12]. However, several previous studies investigated whether being overweight was associated with better survival outcomes in critically ill patients, including the post-resuscitation state, and this phenomenon is called the obesity paradox [13-15]. A large, multicentre, prospective study with data from a national registry showed that the BMI groups had similar rates of survival, except underweight patients with IHCA caused by non-shockable rhythm [16]. A meta-analysis that evaluated the effect of BMI on survival post resuscitation showed that overweight patients had a favourable outcome considering both survival and neurologic outcomes, especially in patients who experienced IHCA and patients without therapeutic hypothermia [17].

To the best of our knowledge, data are limited, and the results are debatable regarding the effect of obesity on the survival and neurologic outcomes of patients who experienced OHCA. Therefore, by using data from a nationwide multicentre registry, the current study aimed to assess the association between the outcomes and BMI in the four BMI groups after resuscitation in patients who experienced OHCA. We hypothesised that the neurologic outcomes after survival from the time of admission in patients who experienced OHCA would differ according to the BMI.

\section{Methods}

\section{Study design and setting}

We conducted the current multicentre prospective observational study using data from the Korean Cardiac Arrest Resuscitation Consortium (KoCARC) registry, which is a nationwide OHCA registry based on the Utstein templates and a hospital-based collaborative research network. The KoCARC registry included patients with OHCA transported to the participating emergency departments via emergency medical services with resuscitation efforts and who had a medical aetiology identified by emergency physicians. The registry excluded patients with a terminal illness documented in medical records, patients under hospice care, pregnant patients, and patients with a previously documented 'Do Not Resuscitate' card. Patients with cardiac arrest due to definite non-medical aetiology were also excluded, including trauma, drowning, poisoning, burn, asphyxia, or hanging. The data were collected via a standardised registry form and uploaded into a web-based electronic database registry; the quality of this registry is controlled by the quality management committee $[18,19]$. The project was registered at ClinicalTrials.gov (identifier NCT03222999) and ethically reviewed and approved by the institutional review board (IRB) of the 62 participating hospitals. The study was waived for informed consent by the IRB.

\section{Study population}

The KoCARC registry consists of core variables and supplemental variables. The participating hospital can decide to investigate each of the supplemental variables, including height and weight. Among the participating hospitals, we enrolled hospitals willing to include height and weight to minimise potential risk for bias. We included patients who survived the trip to the hospitalfor admission to the enrolled hospital from the KoCARC registry-between October 2015 and June 2018. We excluded patients who were aged $<18$ years, those who were transferred from other hospitals to the enrolled hospital, and those without any information about weight, height, or the Cerebral Performance Category (CPC). Additionally, we compared the baseline characteristics between the whole cohort of the registry and enrolled patients.

\section{Data extraction and definition}

Information about the KoCARC database, data elements, and quality assurance has been previously published [19]. We extracted the following KoCARC core data and supplementary variables: 1) Patient domain: age, sex, witnessed arrest, arrest location, bystander cardiopulmonary resuscitation (CPR), first monitored rhythm, comorbidities (hypertension, diabetes, and dyslipidaemia). 2) Pre-return of spontaneous circulation (ROSC) process 
domain: response times (no-flow time was defined as the time between the cardiac arrest and the initiation of CPR by a medical provider; low flow time was defined as the time between active CPR by a bystander and/or a medical provider and ROSC; it is equal to the total arrest time minus the no-flow time), pre-hospital ROSC was defined as the restoration of a palpable pulse before arrival at the hospital, pre-hospital adrenaline use, prehospital airway control type (bag-valve mask, supraglottic airway, or endotracheal intubation). 3) Postresuscitation process domain: mental state at admission (alert, drowsy to stuporous, or coma), reperfusion coronary angiography (CAG), CAG and percutaneous coronary intervention (PCI), tissue plasminogen activator (tPA), targeted temperature management (TTM), $\mathrm{pH}$, lactate, glucose, first systolic/diastolic blood pressure, and pulse rate after ROSC. The enrolled patients were classified into the underweight $\left(<18.5 \mathrm{~kg} / \mathrm{m}^{2}\right)$, normal weight ( $\geq 18.5$ to $<25 \mathrm{~kg} / \mathrm{m}^{2}$ ), overweight ( $\geq 25$ to $<30$ $\left.\mathrm{kg} / \mathrm{m}^{2}\right)$, and obese groups $\left(\geq 30 \mathrm{~kg} / \mathrm{m}^{2}\right)$ according to the BMI per the World Health Organization (WHO) criteria.

\section{Outcome variables and subgroup analysis}

The primary outcome was a favourable neurologic outcome defined as CPC of 1 or 2 at the time of hospital discharge. Patients had a CPC of 1 if they had good cerebral performance and were conscious, alert, and able to work with a possible mild neurologic or psychological deficit. Patients had a CPC of 2 if they had a moderate cerebral disability and were conscious, had sufficient cerebral function for independent activities of daily life, and were able to work in sheltered environments. This performance scale indicates mortality as a CPC of 5 , defined as death or brain death [20]. The secondary outcome was survival to discharge, and we investigated factors that affected mortality. Moreover, we classified patients into the TTM and non-TTM groups and compared the favourable neurologic outcome and survival discharge according to the BMI in each group after adjusting the confounders.

\section{Statistical analysis}

The KoCARC registry compiled and released data with a standard spreadsheet application (Excel 2016; Microsoft, Redmond, USA). Continuous baseline variables were presented as the median and interquartile range and analysed using the Shapiro-Wilk test for normality distribution. The Kruskal-Wallis test was used to compare groups with unsatisfied to normally distributed continuous variables. Categorical variables were presented as the number and percentages and analysed by using a chisquared test. Two-tailed $p$-values $<0.05$ indicated a significant difference. The logistic regression method was used for multivariate analysis to determine the association between the BMI and CPC at discharge and the survival discharge rate, independent of the confounders. The Hosmer-Lemeshow test was used to confirm the logistic model calibrations. Subgroup analysis was performed using forest plots, and the p-values were calculated for determining the effect of TTM on the association between the BMI and outcomes. SAS 9.4 (SAS Institute Inc., Cary, USA) and MedCalc version 17.2 (MedCalc Software, Ostend, Belgium) were used for all analyses.

\section{Results}

Among 33 hospitals, 9 hospitals entered the weight and height of the registered patients. A total of 773 patients who survived to admission after OHCA were eligible; 168 patients were excluded according to the exclusion criteria: 136 were transferred from other hospitals, and 32 had missing data for height, weight, or CPC. Finally, 605 patients were included in our analysis and categorised per the WHO BMI classification (Fig. 1).

The baseline characteristics of all the included patients and those in each BMI group are summarised in Table 1 and the comparison with the whole registry in Supplemental Table 1. There were significant differences among the four groups in age, first monitored rhythm by emergency medical services, performance of TTM, pre-hospital ROSC, reperfusion attempt, and first serum lactate and glucose levels. Patients in the underweight group $(n=75,12.4 \%)$ were relatively older and did not regularly show shockable rhythm in the first monitored rhythm when compared to those in the other groups. Moreover, patients in the underweight group experienced pre-hospital ROSC and treatment with TTM and reperfusion therapy with lower frequency than those in the other groups did. Furthermore, the first checked serum glucose levels were lower, and the lactate levels were higher in the underweight group than in the other groups. Other variables-including sex, witness arrest, bystander CPR, comorbidities, duration of cardiac arrest, and mentation at admission-were not significantly different among the groups.

The primary and secondary outcomes, according to the BMI classification, are summarised in Table 2. A favourable neurologic outcome was observed less frequently in the underweight group than in the other groups $(p=0.002)$, and survival to discharge was not significantly different among the groups $(p=0.110)$.

Univariate and multivariate analyses of factors associated with favourable neurologic outcomes were performed to adjust confounders that could affect the primary outcome (Table 3). On univariate analysis, the underweight group was less frequently (odds ratio [OR], 0.305 ; $95 \%$ confidence interval $[\mathrm{CI}], 0.155-0.601, p=$ 


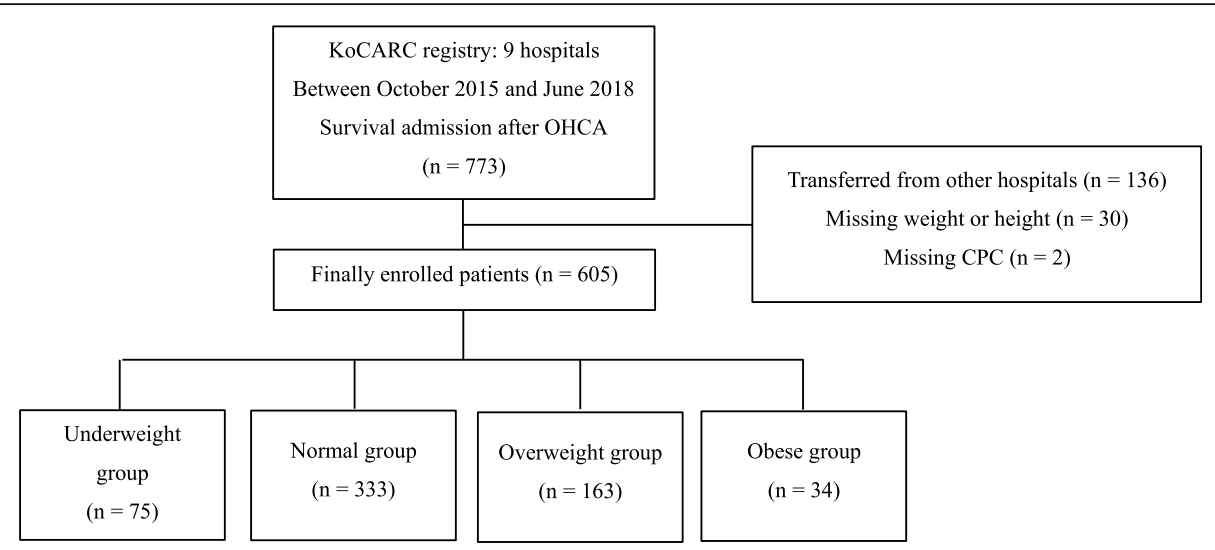

Fig. 1 Flow chart of the study. KoCARC, Korean Cardiac Arrest Resuscitation Consortium; OHCA, out-of-hospital cardiac arrest; CPC, Cerebral Performance Category

$0.003)$ and the obese group was more frequently (OR, 1.401; 95\% CI, 0.687-2.859, $p=0.040$ ) associated with favourable neurologic outcomes and survival to discharge than the normal group. Significant differences were observed in age, first monitored rhythm, low flow time, pre-hospital ROSC, mentation at admission, and reperfusion therapy on both univariate and multivariate analyses. However, the BMI was not associated with favourable neurologic outcomes after adjusting for confounders on multivariate analysis.

Survival to discharge was associated with age, first monitored rhythm, diabetes, low flow time, pre-hospital ROSC, and mentation at admission on multivariate analysis. The underweight group had a lower rate of survival to discharge than the normal BMI group on univariate analysis (OR, 0.531; 95\% CI, 0.318-0.889, $p=0.030$ ). However, underweight, overweight, and obese BMI were not risk factors for survival to discharge after adjusting for influencing factors on multivariate analysis by using a logistic regression model (Table 4).

On subgroup analysis, a low or high BMI was not a risk factor for poor neurologic outcomes or in-hospital mortality in both the TTM and non-TTM groups on multivariate analysis (Fig. 2).

\section{Discussion}

In the current study, we aimed to investigate the relationship between the BMI and neurologic and survival outcomes of patients successfully resuscitated from OHCA. We found there were no significant differences in the survival outcomes among the four BMI groups. A favourable neurologic outcome was higher in the obese group and lower in the underweight group on univariate analysis. However, no differences were found after adjusting the confounding factors.

In previous studies and meta-analyses, there were no unified results about the association between the BMI and outcomes after cardiac arrest. A recent meta-analysis showed that the hospital survival rate was lower in the underweight group and higher in the overweight group, but no difference was found on a subgroup analysis of patients who experienced OHCA only [21]. Moreover, another meta-analysis found that overweight patients had better survival and neurologic outcomes after cardiac arrest, and it was amplified in the IHCA with TTM group [17]. However, these meta-analyses did not reflect confounding factors, and the result was different according to the included studies.

A multicentre prospective study showed that patients with a BMI $>30 \mathrm{~kg} / \mathrm{m}^{2}$ had higher 30-day mortality among patients resuscitated from OHCA and managed with TTM [22]. In the present study, no differences were found in both neurologic and survival outcomes when the obese and normal groups managed with TTM were compared. Bunch et al. reported that the discharge rates and favourable neurologic outcomes were similar between the BMI groups among patients with ventricular fibrillation during OHCA [23]. They did not analyse the underweight group separately and only included a relatively small number of variables. The results of the current study showed that the underweight group had lower favourable neurologic outcomes and lower survival discharge rates than the normal weight group did on univariate analysis. However, there were no differences after adjusting the confounding factors. In line with the results of the current study, Testori et al. reported no relationship between the BMI and 6-month survival rate [14]. However, the overweight group had better neurologic outcomes in cardiac arrest survivors because Testori et al. included both OHCA and IHCA and adjusted fewer factors such as pre-hospital factors, age, and comorbidities. In the present study, we included only OHCA and adjusted more factors, including the mentation state, reperfusion attempt, and laboratory findings.

According to the results of a large, multicentre, prospective registry-based study about BMI and survival 
Table 1 Baseline characteristics stratified by body mass index

\begin{tabular}{|c|c|c|c|c|c|c|}
\hline Variables & $\begin{array}{l}\text { Total } \\
(n=605)\end{array}$ & $\begin{array}{l}\text { Underweight } \\
\text { group } \\
(n=75)\end{array}$ & $\begin{array}{l}\text { Normal } \\
\text { group } \\
(n=333)\end{array}$ & $\begin{array}{l}\text { Overweight } \\
\text { group } \\
(n=163)\end{array}$ & $\begin{array}{l}\text { Obese } \\
\text { group } \\
(n=34)\end{array}$ & $p$-value* \\
\hline \multicolumn{7}{|l|}{ Patient domain } \\
\hline Age, years, median (IQR) & $63(53-74)$ & $71(62-79)$ & $63(54-75)$ & $61(51-72)$ & $56.5(42-72)$ & $<.001$ \\
\hline Sex, male (\%) & $422(69.75)$ & $53(70.67)$ & $233(69.97)$ & $115(70.55)$ & $21(61.76)$ & 0.774 \\
\hline Witnessed arrest (\%) & $449(74.21)$ & $55(73.33)$ & $244(73.27)$ & $125(76.69)$ & $25(73.53)$ & 0.870 \\
\hline \multicolumn{7}{|l|}{ Arrest location $(n=601)$} \\
\hline Home/residence (\%) & $320(53.24)$ & $48(64)$ & $172(52.12)$ & $85(52.47)$ & $15(44.12)$ & 0.185 \\
\hline Other (\%) & $281(46.76)$ & $27(36)$ & $158(47.88)$ & $77(47.53)$ & $19(55.88)$ & \\
\hline \multicolumn{7}{|l|}{ Bystander response $(n=602)$} \\
\hline CPR by bystander (\%) & $307(51)$ & $39(52.7)$ & $164(49.4)$ & $84(51.53)$ & $20(60.61)$ & 0.645 \\
\hline No CPR by bystander (\%) & $295(49)$ & $35(47.3)$ & $168(50.6)$ & $79(48.47)$ & 13 (39.39) & \\
\hline \multicolumn{7}{|l|}{ First monitored rhythm $(n=597)$} \\
\hline Shockable rhythm (\%) & $250(41.88)$ & $11(14.86)$ & $149(45.29)$ & $72(45)$ & $18(52.94)$ & $<.001$ \\
\hline Non-shockable rhythm (\%) & $347(58.12)$ & $63(85.14)$ & $180(54.71)$ & $88(55)$ & $16(47.06)$ & \\
\hline \multicolumn{7}{|l|}{ Comorbidities $(n=603)$} \\
\hline Hypertension (\%) & $294(48.76)$ & $31(41.33)$ & $153(46.08)$ & $93(57.41)$ & $17(50)$ & 0.058 \\
\hline Diabetes (\%) & $190(31.51)$ & $16(21.33)$ & $102(30.72)$ & $60(37.04)$ & $12(35.29)$ & 0.102 \\
\hline Dyslipidaemia (\%) & $40(6.63)$ & $2(2.67)$ & $22(6.63)$ & $12(7.41)$ & $4(11.76)$ & 0.320 \\
\hline \multicolumn{7}{|l|}{ Pre-ROSC process domain } \\
\hline No flow time, minutes, median (IQR) & $7(5-10)$ & $6(3-10)$ & $7(5-11)$ & $7(5-10)$ & $6(5-10)$ & 0.446 \\
\hline Low flow time, minutes, median (IQR) $(n=604)$ & $25(12-40)$ & $26(18-38)$ & $24.5(11-39)$ & $25(11-42)$ & $24.5(15-54)$ & 0.655 \\
\hline Pre-hospital ROSC (\%) & $206(34.05)$ & $15(20)$ & $129(38.74)$ & $51(31.29)$ & $11(32.35)$ & 0.015 \\
\hline Pre-hospital adrenaline use (\%) & $62(10.25)$ & $5(6.67)$ & $39(11.71)$ & $16(9.82)$ & $2(5.88)$ & 0.465 \\
\hline \multicolumn{7}{|l|}{ Pre-hospital airway } \\
\hline Bag-valve mask (\%) & 234 (38.68) & $34(45.33)$ & $120(36.04)$ & $66(40.49)$ & $14(41.18)$ & 0.427 \\
\hline Supraglottic airway (\%) & 300 (49.59) & $29(38.67)$ & $173(51.95)$ & $82(50.31)$ & $16(47.06)$ & \\
\hline Endotracheal intubation (\%) & $71(11.74)$ & $12(16)$ & $40(12.01)$ & $15(9.2)$ & $4(11.76)$ & \\
\hline \multicolumn{7}{|l|}{ Post-ROSC process domain } \\
\hline \multicolumn{7}{|l|}{ Mental state at admission } \\
\hline Alert (\%) & $60(9.92)$ & $4(5.33)$ & $33(9.91)$ & $20(12.27)$ & $3(8.82)$ & 0.333 \\
\hline Drowsy to stuporous (\%) & $63(10.41)$ & $6(8)$ & $30(9.01)$ & $22(13.5)$ & $5(14.71)$ & \\
\hline Coma (\%) & $482(79.67)$ & $65(86.67)$ & $270(81.08)$ & $121(74.23)$ & $26(76.47)$ & \\
\hline \multicolumn{7}{|l|}{ Reperfusion attempted } \\
\hline None (\%) & $297(49.09)$ & $52(69.33)$ & $164(49.25)$ & $68(41.72)$ & $13(38.24)$ & 0.002 \\
\hline CAG only (\%) & $170(28.1)$ & $10(13.33)$ & $93(27.93)$ & $54(33.13)$ & $13(38.24)$ & \\
\hline CAG and PCI (\%) & $96(15.87)$ & $6(8)$ & $60(18.02)$ & $26(15.95)$ & $4(11.76)$ & \\
\hline tPA (\%) & $42(6.94)$ & $7(9.33)$ & $16(4.8)$ & $15(9.2)$ & $4(11.76)$ & \\
\hline TTM (\%) & $225(37.19)$ & $17(22.67)$ & $122(36.64)$ & $72(44.17)$ & $14(41.18)$ & 0.015 \\
\hline $\mathrm{pH}$, median $(\mathrm{IQR})(n=600)$ & $\begin{array}{l}7.07 \\
(6.92-7.25)\end{array}$ & $\begin{array}{l}7.06 \\
(6.95-7.27)\end{array}$ & $\begin{array}{l}7.11 \\
(6.91-7.27)\end{array}$ & $\begin{array}{l}7.03 \\
(6.9-7.22)\end{array}$ & $\begin{array}{l}7.11 \\
(6.98-7.28)\end{array}$ & 0.212 \\
\hline Lactate, $\mathrm{mmol} / \mathrm{l}$, median (IQR) $(n=593)$ & $10.6(7.6-14)$ & $11.7(9-14.39)$ & $\begin{array}{l}10.285 \\
(7.2-13.2)\end{array}$ & $\begin{array}{l}11 \\
(8.2-15.29)\end{array}$ & $9.4(6.5-13.2)$ & 0.008 \\
\hline Glucose, mg/dl, median (IQR) $(n=603)$ & $\begin{array}{l}265 \\
(193-338)\end{array}$ & $229(146-313)$ & $268(207-335)$ & $\begin{array}{l}265 \\
(190-378)\end{array}$ & $\begin{array}{l}268.5 \\
(228-362)\end{array}$ & 0.039 \\
\hline First systolic BP after ROSC, mmHg, median (IQR) $(n=590)$ & 122.5 & $130(80-149)$ & $120(90-149)$ & 124.5 & $121(98-156)$ & 0.482 \\
\hline
\end{tabular}


Table 1 Baseline characteristics stratified by body mass index (Continued)

\begin{tabular}{|c|c|c|c|c|c|c|}
\hline Variables & $\begin{array}{l}\text { Total } \\
(n=605)\end{array}$ & $\begin{array}{l}\text { Underweight } \\
\text { group } \\
(n=75)\end{array}$ & $\begin{array}{l}\text { Normal } \\
\text { group } \\
(n=333)\end{array}$ & $\begin{array}{l}\text { Overweight } \\
\text { group } \\
(n=163)\end{array}$ & $\begin{array}{l}\text { Obese } \\
\text { group } \\
(n=34)\end{array}$ & $p$-value* \\
\hline & $(92-152)$ & & & $(95.5-160)$ & & \\
\hline First diastolic BP after ROSC, mmHg, median (IQR) $(n=589)$ & 75 (59-93) & $79(56-93)$ & $74(56-91)$ & $77(60-96)$ & $72(57-90)$ & 0.428 \\
\hline First pulse rate after ROSC, beats/min, median (IQR) $(n=586)$ & $100(81-123)$ & $99(75-132)$ & $96(79-120)$ & $108(87-124)$ & $102(78-116)$ & 0.062 \\
\hline
\end{tabular}

Abbreviations: IQR interquartile range, CAG coronary angiography, $C P R$ cardiopulmonary resuscitation, $P C I$ percutaneous coronary intervention, $R O S C$ return of spontaneous circulation, $P P A$ tissue plasminogen activator, TTM targeted temperature management

Continuous variables are presented as the median (Q1, Q3) and tested by using the Kruskal-Wallis test, and categorical variables are presented as $\mathrm{N}$ (\%) and tested by using the chi-squared test ${ }^{*} p<0.05$ was significant

after IHCA, the survival rates were affected by shockable/non-shockable rhythm and BMI [16]. However, OHCA and IHCA have different baseline characteristics, and underweight patients may have poor nutritional and functional status or severe comorbidities in IHCA, and this is more prominent in IHCA than in OHCA [24].

These various results may be obtained owing to differences in the study population or study design. However, no study investigated the association between the BMI categories and neurologic or survival outcomes of patients surviving after OHCA treated with or without TTM. To the best of our knowledge, the current study is the first to compare the neurologic outcomes between the BMI groups resuscitated after OHCA by using a nationwide multicentre registry including shockable/non-shockable rhythms and the TTM/non-TTM groups.

Obesity is associated with a higher risk of cardiovascular disease, and high-quality CPR is difficult in obese patients [12, 25]. However, overweight and obese patients were relatively younger and frequently showed shockable rhythm [16, 23, 26]. Accordingly, overweight and obese patients more frequently experience ROSC before hospital arrival and are managed with TTM or CAG. The result of the present study showed a similar trend observed in past studies $[14,22]$. Obesity seemed to be associated with a good prognosis on univariate analysis. However, other variables associated with obesity-such as age, first monitored shockable rhythm, and pre-hospital ROSC-were more independently associated with favourable neurologic or survival outcomes than BMI was. Obesity was not independently associated with outcomes after adjusting for these factors. Based on these results, high BMI patients are more likely to suffer arrest with shockable rhythms, hence more likely to have ROSC, live to reach the hospital, and receive TTM.

The current study has several limitations. First, although the registry-based study was prospective, the aim to investigate the association between the BMI and outcomes of ROSC in patients who experienced OHCA was not decided prior to the initiation of the KoCARC registry. Second, because weight and height were not core variables of the KoCARC registry, we could not enrol all participated hospitals. However, there were no differences in the important variables of baseline characteristics between the whole registry and the study cohort. Third, although the registry collected various data based on the Utstein-style templates, and we tried to analyse the maximum possible number of important factors that that could affect outcomes, there may be hidden confounders that could affect outcomes. Fourth, the height or weight might not have been accurately measured, and weight changes during the hospital stay were not investigated in the current study. Finally, the long-term outcomes were unknown. The KoCARC registry collected 6-month data for survival and the neurologic outcome. However, these data were not sufficient because the observation period was too short at the time of data analysis. Therefore, further studies are needed to investigate the association between the $\mathrm{BMI}$ and long-term neurologic and survival outcomes after OHCA.

Table 2 Primary and secondary outcomes of groups according to body mass index classification on univariate analysis

\begin{tabular}{|c|c|c|c|c|c|c|}
\hline Outcomes & $\begin{array}{l}\text { Total } \\
(n=605)\end{array}$ & $\begin{array}{l}\text { Underweight } \\
\text { group } \\
(n=75)\end{array}$ & $\begin{array}{l}\text { Normal } \\
\text { group } \\
(n=333)\end{array}$ & $\begin{array}{l}\text { Overweight } \\
\text { group } \\
(n=163)\end{array}$ & $\begin{array}{l}\text { Obese } \\
\text { group } \\
(n=34)\end{array}$ & $p$-value \\
\hline $\begin{array}{l}\text { Favourable neurologic outcomes at hospital } \\
\text { discharge }\end{array}$ & $\begin{array}{l}202 \\
(33.39)\end{array}$ & $11(14.67)$ & $120(36.04)$ & $56(34.36)$ & $15(44.12)$ & 0.002 \\
\hline Survival to discharge & $\begin{array}{l}303 \\
(50.08)\end{array}$ & $28(37.33)$ & $176(52.85)$ & 81 (49.69) & $18(52.94)$ & 0.111 \\
\hline
\end{tabular}

All variables are presented as the $\mathrm{N}(\%)$ and tested by using the chi-squared test 
Table 3 Univariate and multivariate analyses of factors affecting favourable neurologic outcomes

\begin{tabular}{|c|c|c|c|c|c|c|}
\hline \multirow[t]{2}{*}{ Variables } & \multicolumn{3}{|c|}{ Univariate analysis } & \multicolumn{3}{|c|}{ Multivariate analysis $(N=559)$} \\
\hline & $\begin{array}{l}\text { Unadjusted } \\
\text { OR }\end{array}$ & $\begin{array}{l}95 \% \mathrm{Cl} \text { for the } \\
\text { OR }\end{array}$ & $p$-value* & $\begin{array}{l}\text { Adjusted } \\
\text { OR }\end{array}$ & $\begin{array}{l}95 \% \mathrm{Cl} \text { for the } \\
\text { OR }\end{array}$ & $p$-value* \\
\hline Age, (per year) & 0.946 & $0.933-0.959$ & $<.001$ & 0.927 & $0.901-0.953$ & $<.001$ \\
\hline Sex, (Female/male) & 0.573 & $0.388-0.844$ & 0.005 & 1.307 & $0.617-2.766$ & 0.484 \\
\hline Witnessed arrest (Yes/No) & 1.503 & $1.004-2.249$ & 0.045 & 0.961 & $0.461-2.003$ & 0.916 \\
\hline Arrest location (Home/Others) & 0.476 & $0.337-0.672$ & $<.001$ & 0.703 & $0.366-1.35$ & 0.290 \\
\hline $\begin{array}{l}\text { Bystander response (CPR performed/CPR not } \\
\text { performed) }\end{array}$ & 2.069 & $1.463-2.927$ & $<.001$ & 0.658 & $0.325-1.332$ & 0.245 \\
\hline First monitored rhythm (Shockable/Non-shockable) & 14.456 & $9.456-22.101$ & $<.001$ & 5.869 & $2.646-13.018$ & $<.001$ \\
\hline Hypertension (Present/Absent) & 0.573 & $0.406-0.808$ & 0.002 & 1.193 & $0.579-2.459$ & 0.632 \\
\hline Diabetes (Present/Absent) & 0.449 & $0.302-0.667$ & $<.001$ & 0.547 & $0.252-1.188$ & 0.127 \\
\hline Dyslipidaemia (Present/Absent) & 1.685 & $0.882-3.22$ & 0.114 & & & \\
\hline No flow time, (per minute) & 0.992 & $0.97-1.014$ & 0.470 & & & \\
\hline Low flow time, (per minute) & 0.907 & $0.891-0.923$ & $<.001$ & 0.962 & $0.938-0.987$ & 0.003 \\
\hline Pre-hospital ROSC (Observed/Not observed) & 19.647 & $12.791-30.18$ & $<.001$ & 3.762 & $1.442-9.813$ & 0.007 \\
\hline Pre-hospital adrenaline (Used/Not used) & 0.446 & $0.232-0.858$ & 0.016 & 1.103 & $0.319-3.814$ & 0.877 \\
\hline \multicolumn{7}{|l|}{ Pre-hospital airway } \\
\hline Bag-valve mask & Reference & - & - & & & \\
\hline Supraglottic airway & 0.769 & $0.537-1.101$ & 0.152 & & & \\
\hline Endotracheal intubation & 0.606 & $0.337-1.092$ & 0.095 & & & \\
\hline \multicolumn{7}{|l|}{ Mental state at admission } \\
\hline Alert & Reference & - & - & Reference & - & - \\
\hline Drowsy to stuporous & 0.357 & $0.136-0.938$ & 0.037 & 3.924 & $0.81-19.022$ & 0.006 \\
\hline Coma & 0.036 & $0.016-0.081$ & $<.001$ & 0.226 & $0.065-0.782$ & $<.001$ \\
\hline \multicolumn{7}{|l|}{ Reperfusion attempted } \\
\hline None & Reference & - & - & Reference & - & - \\
\hline CAG only & 9.106 & $5.818-14.252$ & $<.001$ & 2.636 & $1.193-5.823$ & 0.057 \\
\hline CAG and $\mathrm{PCl}$ & 7.482 & $4.457-12.561$ & $<.001$ & 5.027 & $1.869-13.521$ & 0.001 \\
\hline tPA & 0.821 & $0.305-2.207$ & 0.696 & 0.353 & $0.069-1.802$ & 0.021 \\
\hline TTM (Performed/Not performed) & 0.934 & $0.658-1.327$ & 0.705 & & & \\
\hline $\mathrm{pH}$ & 632.387 & 193.43-999.999 & $<.001$ & 1.706 & $0.196-14.837$ & 0.628 \\
\hline Lactate (per mmol/l) & 0.858 & $0.821-0.897$ & $<.001$ & 0.972 & $0.893-1.058$ & 0.513 \\
\hline Glucose (per mg/dl) & 0.998 & $0.996-0.999$ & 0.008 & 0.998 & $0.994-1.001$ & 0.136 \\
\hline First systolic BP after ROSC, (per mmHg) & 1.007 & $1.003-1.011$ & 0.003 & 1.011 & $0.996-1.025$ & 0.145 \\
\hline First diastolic BP after ROSC, (per mmHg) & 1.024 & $1.017-1.032$ & $<.001$ & 1.013 & $0.991-1.036$ & 0.253 \\
\hline First pulse rate after ROSC, (per beat/min) & 1.000 & $0.994-1.005$ & 0.993 & & & \\
\hline \multicolumn{7}{|l|}{$\mathrm{BMI}, \mathrm{kg} / \mathrm{m}^{2}$} \\
\hline 18.5 to 24.9 & Reference & - & - & Reference & - & - \\
\hline$<18.5$ & 0.305 & $0.155-0.601$ & 0.003 & 0.656 & $0.185-2.325$ & 0.358 \\
\hline 25.0 to 29.9 & 0.929 & $0.627-1.376$ & 0.366 & 0.658 & $0.301-1.441$ & 0.187 \\
\hline$>30.0$ & 1.401 & $0.687-2.859$ & 0.040 & 2.722 & $0.65-11.401$ & 0.087 \\
\hline
\end{tabular}

Abbreviations: $B M I$ body mass index, $C A G$ coronary angiography, $C l$ confidence interval, $C P R$ cardiopulmonary resuscitation, $O R$ odds ratio, $P C l$ percutaneous coronary intervention, $R O S C$ return of spontaneous circulation, $I P A$ tissue plasminogen activator, $T M M$ targeted temperature management ${ }^{*} p<0.05$ was significant 
Table 4 Univariate and multivariate analyses of factors affecting survival to discharge

\begin{tabular}{|c|c|c|c|c|c|c|}
\hline \multirow[t]{2}{*}{ Variables } & \multicolumn{3}{|c|}{ Univariate analysis } & \multicolumn{3}{|c|}{ Multivariate analysis $(\mathrm{N}=559)$} \\
\hline & $\begin{array}{l}\text { Unadjusted } \\
\text { OR }\end{array}$ & $\begin{array}{l}95 \% \mathrm{Cl} \text { for the } \\
\text { OR }\end{array}$ & $p$-value* & $\begin{array}{l}\text { Adjusted } \\
\text { OR }\end{array}$ & $\begin{array}{l}95 \% \mathrm{Cl} \text { for the } \\
\text { OR }\end{array}$ & $p$-value* \\
\hline Age, (per year) & 0.958 & $0.947-0.97$ & $<.001$ & 0.971 & $0.953-0.989$ & 0.001 \\
\hline Sex, (Female/male) & 0.61 & $0.43-0.867$ & 0.006 & 0.789 & $0.478-1.302$ & 0.354 \\
\hline Witnessed arrest (Yes/No) & 1.695 & $1.171-2.453$ & 0.005 & 1.434 & $0.849-2.422$ & 0.178 \\
\hline Arrest location (Home/Others) & 0.513 & $0.371-0.71$ & $<.001$ & 0.783 & $0.491-1.249$ & 0.305 \\
\hline $\begin{array}{l}\text { Bystander response (CPR performed/CPR not } \\
\text { performed) }\end{array}$ & 1.707 & $1.236-2.356$ & 0.001 & 1.194 & $0.741-1.923$ & 0.467 \\
\hline First monitored rhythm (Shockable/Non-shockable) & 6.098 & $4.244-8.761$ & $<.001$ & 2.762 & $1.505-5.068$ & 0.001 \\
\hline Hypertension (Present/Absent) & 0.64 & $0.464-0.883$ & 0.007 & 1.073 & $0.64-1.799$ & 0.790 \\
\hline Diabetes (Present/Absent) & 0.409 & $0.286-0.583$ & $<.001$ & 0.381 & $0.221-0.657$ & 0.001 \\
\hline Dyslipidaemia (Present/Absent) & 1.101 & $0.579-2.093$ & 0.769 & & & \\
\hline No flow time, (per minute) & 0.984 & $0.964-1.005$ & 0.142 & & & \\
\hline Low flow time, (per minute) & 0.939 & $0.927-0.95$ & $<.001$ & 0.969 & $0.953-0.986$ & $<.001$ \\
\hline Pre-hospital ROSC (Observed/Not observed) & 10.845 & $7.075-16.624$ & $<.001$ & 2.161 & $1.011-4.619$ & 0.047 \\
\hline Pre-hospital adrenaline (Used/Not used) & 0.474 & $0.273-0.824$ & 0.008 & 0.639 & $0.283-1.443$ & 0.281 \\
\hline \multicolumn{7}{|l|}{ Pre-hospital airway } \\
\hline Bag-valve mask & Reference & - & - & & & \\
\hline Supraglottic airway & 0.802 & $0.569-1.129$ & 0.206 & & & \\
\hline Endotracheal intubation & 0.703 & $0.413-1.199$ & 0.196 & & & \\
\hline \multicolumn{7}{|l|}{ Mental state at admission } \\
\hline Alert & Reference & - & - & Reference & - & - \\
\hline Drowsy to stuporous & 0.43 & $0.14-1.321$ & 0.141 & 1.685 & $0.433-6.559$ & 0.067 \\
\hline Coma & 0.062 & $0.025-0.158$ & $<.001$ & 0.451 & $0.146-1.397$ & 0.005 \\
\hline \multicolumn{7}{|l|}{ Reperfusion attempted } \\
\hline None & Reference & - & - & Reference & - & - \\
\hline CAG only & 5.003 & $3.307-7.567$ & $<.001$ & 1.58 & $0.84-2.973$ & 0.197 \\
\hline CAG and $\mathrm{PCl}$ & 2.832 & $1.764-4.548$ & $<.001$ & 0.923 & $0.438-1.945$ & 0.385 \\
\hline tPA & 1.262 & $0.652-2.443$ & 0.490 & 1.293 & $0.555-3.013$ & 0.765 \\
\hline TTM (Performed/Not performed) & 1.34 & $0.962-1.865$ & 0.083 & & & \\
\hline $\mathrm{pH}$ & 89.557 & $34.575-231.976$ & $<.001$ & 1.572 & $0.375-6.59$ & 0.536 \\
\hline Lactate (per mmol/l) & 0.868 & $0.835-0.903$ & $<.001$ & 0.958 & $0.907-1.011$ & 0.115 \\
\hline Glucose (per mg/dl) & 0.998 & $0.997-0.999$ & 0.002 & 1 & $0.998-1.002$ & 0.985 \\
\hline First systolic BP after ROSC, (per mmHg) & 1.008 & $1.004-1.012$ & $<.001$ & 1.009 & $1-1.018$ & 0.054 \\
\hline First diastolic BP after ROSC, (per mmHg) & 1.021 & $1.014-1.028$ & $<.001$ & 0.999 & $0.983-1.015$ & 0.931 \\
\hline First pulse rate after ROSC, (per beat/min) & 1.003 & $0.997-1.008$ & 0.340 & & & \\
\hline \multicolumn{7}{|l|}{$\mathrm{BMI}, \mathrm{kg} / \mathrm{m}^{2}$} \\
\hline 18.5 to 24.9 & Reference & - & - & Reference & - & - \\
\hline$<18.5$ & 0.531 & $0.318-0.889$ & 0.030 & 0.854 & $0.425-1.719$ & 0.889 \\
\hline 25.0 to 29.9 & 0.881 & $0.606-1.282$ & 0.697 & 0.856 & $0.49-1.495$ & 0.861 \\
\hline$>30.0$ & 1.004 & $0.495-2.035$ & 0.474 & 0.621 & $0.211-1.823$ & 0.496 \\
\hline
\end{tabular}

Abbreviations: $B M I$ body mass index, $C A G$ coronary angiography, $C l$ confidence interval, $C P R$ cardiopulmonary resuscitation, $O R$ odds ratio, $P C I$ percutaneous coronary intervention, ROSC return of spontaneous circulation, $t P A$ tissue plasminogen activator, $T$ TM targeted temperature management ${ }^{*} p<0.05$ was significant 
A)

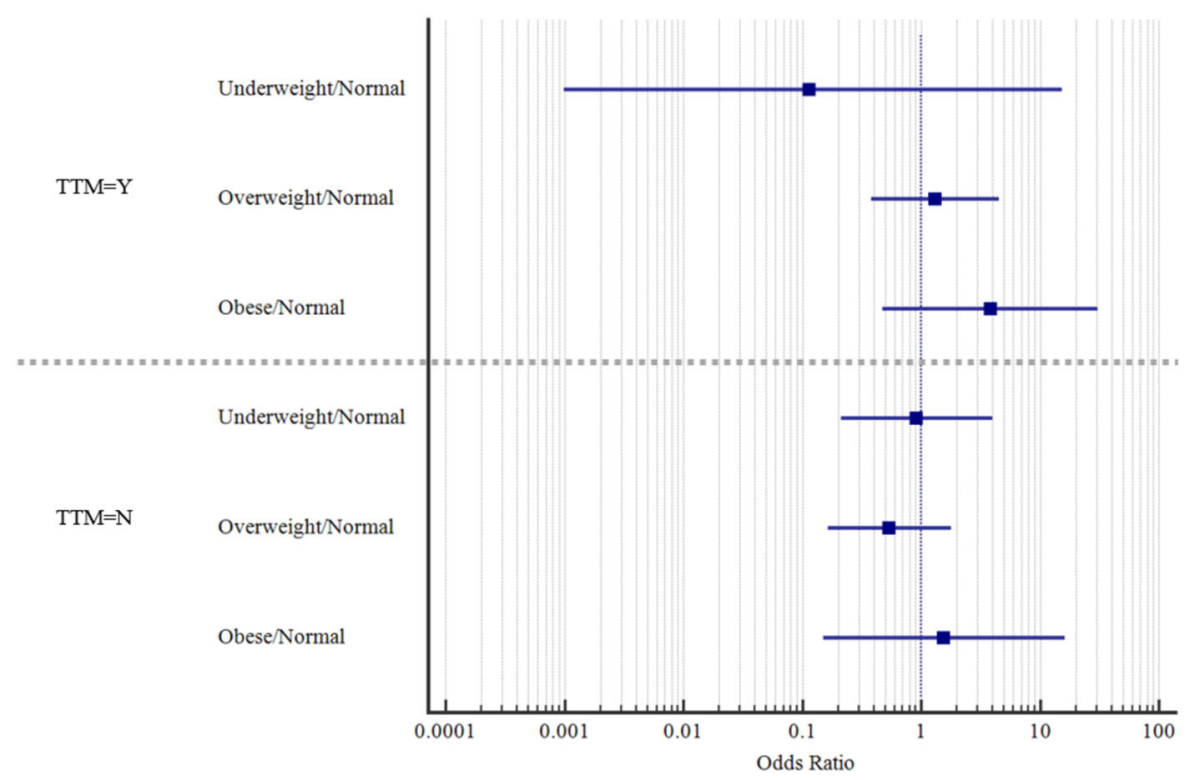

B)

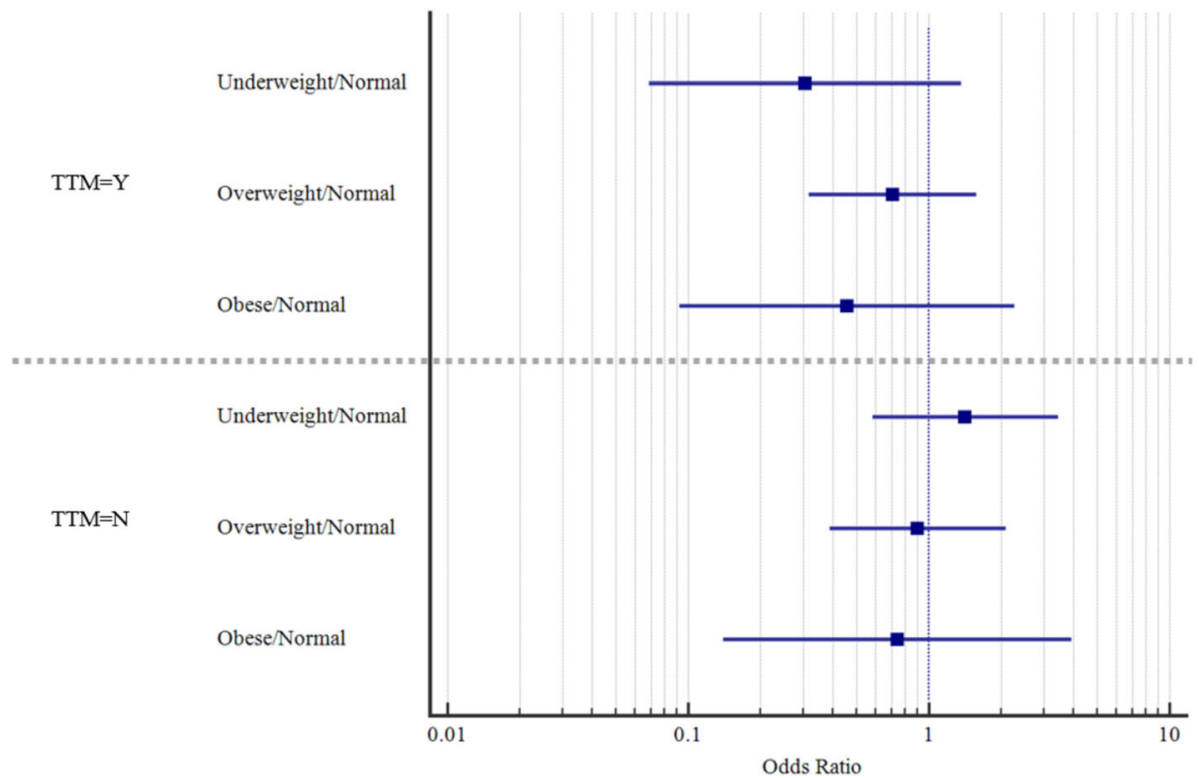

Fig. 2 Comparison of the odds ratios between the body mass index groups for (a) favourable neurologic outcomes $(p=0.429)$ and (b) survival to discharge $(p=0.295)$ according to whether targeted temperature management was performed

\section{Conclusions}

In this study, we found that BMI is not independently associated with favourable neurologic and survival outcomes in patients surviving after OHCA when the confounding factors were adjusted.

\section{Supplementary Information}

The online version contains supplementary material available at https://doi. org/10.1186/s13049-021-00837-x

Additional file 1: Figure S1. Proportion of each CPC categories by body mass index classification, A) Total enrolled patients B) patients 
managed with targeted temperature management C) patients not managed with targeted temperature management.

Additional file 2: Table S1. Comparison of baseline characteristics between patients of KoCARC registry and the study cohort.

\section{Abbreviations}

BMI: Body mass index; OHCA: Out-of-hospital cardiac arrest; IHCA: In-hospital cardiac arrest; KoCARC: Korean Cardiac Arrest Resuscitation Consortium; CPC: Cerebral Performance Category; ROSC: Return of spontaneous circulation; CPR: Cardiopulmonary resuscitation; CAG: Coronary angiography; $\mathrm{PCl}$ : Percutaneous coronary intervention; tPA: tissue plasminogen activator; TTM: Targeted temperature management; WHO: World Health Organization; OR: Odds ratio; Cl: Confidence interval

\section{Acknowledgments}

We would like to acknowledge and thank to investigators from all participating hospitals of KoCARC:

Do Kyun Kim (Seoul National University Hospital), Sang Kuk Han, Phil Cho Choi (Kangbuk Samsung Medical Center), Sang O Park, Jong Won Kim (Konkuk University Medical Center), Han Sung Choi (Kyung Hee University Hospital), Sung Hyuk Choi (Korea University Guro Hospital), Min Seob Sim, Gun Tak Lee (Samsung Medical Center), Shin Ahn (Asan Medical Center), Jong Whan Shin (SMG-SNU Boramae Medical Center), Sang Hyun Park, Keun Hong Park (Seoul Medical Center), In Cheol Park (Yonsei University Severance Hospital), Tae Young Kong (Yonsei University Gangnam Severance Hospital), Kyoung Won Lee, Chu Hyun Kim (Inje University Seoul Paik Hospital), Youngsuk Cho (Hallym University Kangdong Sacred Heart Hospital), Gu Hyun Kang, Yong Soo Jang (Hallym University Kangnam Sacred Heart Hospital), Seok Ran Yeom, Sang Kyoon Han (Pusan National University Hospital), Jae Hoon Lee (Dong-A University Hospital), Jeong Bae Park, Hyun Wook Ryoo (Kyungpook National University Hospital), Kyung Woo Lee, Tae Chang Jang (Daegu Catholic University Medical Center), Jae-hyug Woo (Gachon University Gil Medical Center), Woon Jeong Lee, Seon Hee Woo (The Catholic University of Korea Incheon St. Mary's Hospital), Sung Hyun Yun, Tae Jin Cho (Catholic Kwandong University International St. Mary's Hospital), Sun Pyo Kim, Yong Jin Park (Chosun University Hospital), Jin Woong Lee, Wonjoon Jeong (Chungnam National University Hospital), Sung Soo Park, Jae Kwang Lee (Konyang University Hospital), Ryeok Ahn, Wook Jin Choi (Ulsan University Hospital), Young Gi Min, Eun Jung Park (Ajou University Hospital), Joong Hee Kim (Seoul National University Bundang Hospital), In Byung Kim, Ki Ok Ahn (Myongji Hospital), Han Jin Cho (Korea University Ansan Hospital), Seung Cheol Lee, Sang Hun Lee (Dongguk University Ilsan Hospital), Young Sik Kim, Young Rock Ha (Bundang Jesaeng Hospital), Jin Sik Park, Myoung Woo Lee (Sejong Hospital), Dai Han Wi (Wonkwang University Sanbon Hospital), Sang Ook Ha, Won Seok Yang (Hallym University Pyeongchon Sacred Heart Hospital), Ok Jun Kim, Tae Nyoung Chung (Cha University Bundang Medical Center), Soon Joo Wang, Hang A Park (Hallym University Dongtan Sacred Heart Hospital), Jun Hwi Cho, Chan Woo Park (Kangwon National University Hospital), An Mu Eob, Tae Hun Lee (Hallym University Chuncheon Sacred Heart Hospital), Sang Chul Kim, Hoon Kim (Chungbuk National University Hospital), Han Joo Choi, Chan Young Koh (Dankook University Hospital), Jung Won Lee, Dong Wook Lee (Soonchunhyang University Cheonan Hospital), Tae Oh Jung, Jae Chol Yoon (Chonbuk National University Hospital), Dai Hai Choi, Jung Tae Choi (Dongguk University Gyeongju Hospital), Jin Hee Jeong, Soo Hoon Lee (Gyeongsang National University Hospital), Ji Ho Ryu, Maeng Real Park (Pusan National University Yangsan Hospital), Won Kim (Cheju Halla General Hospital), Sung Wook Song, Woo Jung Kim (Jeju National University Hospital), Joon-myoung Kwon, Eui Hyuk Kang (Mediplex Sejong Hospital), Sang Chan Jin, Tae-kwon Kim (Keimyung University Dongsan Medical Center), Seong Chun Kim (Gyeongsang National University Changwon Hospital). To steering committee, comprised of following individuals:

Sung Oh Hwang (Chair, Wonju Severance Christian Hospital), Sang Do Shin (Chair of Steering Committee, Seoul National University hospital), Hyuk Jun Yang (Advisory Committee, Gachon University Gil hospital), Sung Phil Chung (Data Safety and Management Board, Yonsei University Gangnam Severance Hospital), Sung Woo Lee (Security and Monitoring Board, Korea University Anam hospital), Kyung Jun Song (Secretariat, SMG-SNU Boramae Medical Center), Seung Sik Hwang (Epidemiology and Prevention Research Committee, Seoul National University), Gyu Chong Cho (Community Resuscitation Research Committee, Hallym University Kangdong Sacred Heart Hospital),
Sung Woo Moon (Emergency Medical Service Resuscitation Research Committee, Korea University Ansan Hospital), Kyoung Chul Cha (Hospital Resuscitation Research Committee, Wonju Severance Christian Hospital), Won Young Kim (Hypothermia and Post-Resuscitation Care Research Committee, Asan Medical Center), Sang Hoon Na (Cardiac Care Resuscitation Research Committee, Seoul National University Hospital), Young Ho Kwack (Pediatric Resuscitation Research Committee, Seoul National University hospital). To member of Secretariat: Joo Yeong Kim (Korea University Ansan hospital), Jeong Ho Park (Seoul National University hospital), Sun Young Lee (Seoul National University hospital), and Jung Eun Kim (Seoul National University hospital).

To National Fire Agency for providing prehospital EMS data.

And to Korean Association of Cardiopulmonary Resuscitation (KACPR) for support.

We thank Yun Jin Kim and Donghee Son in the Biostatistical Consulting and Research Lab, Hanyang University for assistance with statistical analysis. This study was supported by the National Research Foundation of Korea (2019R1F1A1063502).

\section{Authors' contributions}

$\mathrm{HL}$ contributed to this study as the first author and JO contributed as a corresponding author. $\mathrm{HL}$ and JO conceived the study and designed the trial. HK, THL, SMP, YHJ, JSL, YSP, YHY, SJK, HJC, YGM supervised the trial procedure and data collection. HL and JO drafted the manuscript, and all authors contributed substantially to its revision. JO takes responsibility for the paper. The author(s) read and approved the final manuscript.

\section{Funding}

None.

\section{Availability of data and materials}

The datasets used and analyzed during the current study are available from the corresponding author on reasonable request.

\section{Ethics approval and consent to participate}

The project was registered at ClinicalTrials.gov (identifier NCT03222999) and ethically reviewed and approved by the institutional review board (IRB) of the 62 participating hospitals. The study was waived for informed consent by the IRB.

\section{Consent for publication}

Not applicable.

\section{Competing interests}

The authors declare no competing interests.

\section{Author details}

${ }^{1}$ Department of Emergency Medicine, College of Medicine, Hanyang University, 222 Wangsimni-ro, Seongdong-gu, Seoul 04763, Republic of Korea. ${ }^{2}$ Department of Emergency Medicine, Seoul National University Bundang Hospital, Gyeonggi-do, Republic of Korea. ${ }^{3}$ Department of Emergency Medicine, College of Medicine, Kyung Hee University, Seoul, Republic of Korea. ${ }^{4}$ Department of Emergency Medicine, Yonsei University College of Medicine, Seoul, Republic of Korea. ${ }^{5}$ Department of Emergency Medicine, College of Medicine, Korea University, Seoul, Republic of Korea. ${ }^{6}$ Department of Emergency Medicine, Ajou University School of Medicine, Suwon, Republic of Korea.

Received: 3 July 2020 Accepted: 14 January 2021 Published online: 28 January 2021

\section{References}

1. World Health Organization. WHO Key Facts - Obesity and Overweight. 2020. (Accessed 20 May 2020, at https://www.who.int/news-room/fact-sheets/ detail/obesity-and-overweight).

2. Flegal KM, Kruszon-Moran D, Carroll MD, Fryar CD, Ogden CL. Trends in obesity among adults in the United States, 2005 to 2014. JAMA. 2016;315: 2284-91.

3. Plourde B, Sarrazin JF, Nault I, Poirier P. Sudden cardiac death and obesity. Expert Rev Cardiovasc Ther. 2014;12:1099-110. 
4. Hubert HB, Feinleib M, McNamara PM, Castelli WP. Obesity as an independent risk factor for cardiovascular disease: a 26-year follow-up of participants in the Framingham heart study. Circulation. 1983;67:968-77.

5. Pietrasik G, Goldenberg I, McNitt S, Moss AJ, Zareba W. Obesity as a risk factor for sustained ventricular tachyarrhythmias in MADIT II patients. J Cardiovasc Electrophysiol. 2007;18:181-4.

6. Sánchez-Iñigo L, Navarro-González D, Fernández-Montero A, PastranaDelgado J, Martínez J. Risk of incident ischemic stroke according to the metabolic health and obesity states in the vascular-metabolic CUN cohort. Int J Stroke. 2017;12:187-91.

7. Lee H, Oh J, Lee J, et al. Retrospective study using computed tomography to compare sufficient chest compression depth for cardiopulmonary resuscitation in obese patients. J Am Heart Assoc. 2019;8:e013948.

8. Lazarus R, Sparrow D, Weiss ST. Effects of obesity and fat distribution on ventilatory function: the normative aging study. Chest. 1997:111:891-8.

9. Secombe P, Sutherland R, Johnson R. Body mass index and thoracic subcutaneous adipose tissue depth: possible implications for adequacy of chest compressions. BMC Res Notes. 2017;10:575

10. Jones RL, Nzekwu MM. The effects of body mass index on lung volumes. Chest. 2006;130:827-33.

11. Lee J, Oh J, Lim TH, et al. Comparison of optimal point on the sternum for chest compression between obese and normal weight individuals with respect to body mass index, using computer tomography: a retrospective study. Resuscitation. 2018;128:1-5.

12. Wang $\mathrm{CH}$, Huang $\mathrm{CH}$, Chang WT, et al. Associations between body size and outcomes of adult in-hospital cardiac arrest: a retrospective cohort study. Resuscitation. 2018;130:67-72

13. Sakr Y, Alhussami I, Nanchal R, et al. Being overweight is associated with greater survival in ICU patients: results from the intensive care over nations audit. Crit Care Med. 2015;43:2623-32.

14. Testori C, Sterz F, Losert H, et al. Cardiac arrest survivors with moderate elevated body mass index may have a better neurological outcome: a cohort study. Resuscitation. 2011;82:869-73.

15. Antonopoulos AS, Tousoulis D. The molecular mechanisms of obesity paradox. Cardiovasc Res. 2017;113:1074-86.

16. Jain R, Nallamothu BK, Chan PS. Body mass index and survival after inhospital cardiac arrest. Circ Cardiovasc Qual Outcomes. 2010;3:490-7.

17. Kakavas S, Georgiopoulos G, Oikonomou D, et al. The impact of body mass index on post resuscitation survival after cardiac arrest: a meta-analysis. Clin Nutr ESPEN. 2018;24:47-53

18. Perkins GD, Jacobs IG, Nadkarni VM, et al. Cardiac arrest and cardiopulmonary resuscitation outcome reports: update of the Utstein resuscitation registry templates for out-of-hospital cardiac arrest. Resuscitation. 2015;96:328-40

19. Kim JY, Hwang SO, Shin SD, et al. Korean cardiac arrest research consortium (KoCARC): rationale, development, and implementation. Clin Exp Emerg Med. 2018:5:165-76.

20. Edgren E, Hedstrand U, Kelsey S, Sutton-Tyrrell K, Safar P. Assessment of neurological prognosis in comatose survivors of cardiac arrest. BRCTI Study Group. Lancet. 1994;343:1055-9.

21. Ma Y, Huang L, Zhang L, Yu H, Liu B. Association between body mass index and clinical outcomes of patients after cardiac arrest and resuscitation: a meta-analysis. Am J Emerg Med. 2018;36:1270-9.

22. Geri G, Savary G, Legriel $\mathrm{S}$, et al. Influence of body mass index on the prognosis of patients successfully resuscitated from out-of-hospital cardiac arrest treated by therapeutic hypothermia. Resuscitation. 2016;109:49-55.

23. Bunch TJ, White RD, Lopez-Jimenez F, Thomas RJ. Association of body weight with total mortality and with ICD shocks among survivors of ventricular fibrillation in out-of-hospital cardiac arrest. Resuscitation. 2008;77:351-5.

24. Virani SS, Alonso A, Benjamin EJ, et al. Heart disease and stroke statistics2020 update: a report from the American Heart Association. Circulation. 2020;141:e139-596.

25. Khan SS, Ning H, Wilkins JT, et al. Association of body mass index with lifetime risk of cardiovascular disease and compression of morbidity. JAMA Cardiol. 2018:3:280-7.

26. Gupta T, Kolte D, Mohananey D, et al. Relation of obesity to survival after inhospital cardiac arrest. Am J Cardiol. 2016;118:662-7.

\section{Publisher's Note}

Springer Nature remains neutral with regard to jurisdictional claims in published maps and institutional affiliations.

Ready to submit your research? Choose BMC and benefit from:

- fast, convenient online submission

- thorough peer review by experienced researchers in your field

- rapid publication on acceptance

- support for research data, including large and complex data types

- gold Open Access which fosters wider collaboration and increased citations

- maximum visibility for your research: over $100 \mathrm{M}$ website views per year

At BMC, research is always in progress.

Learn more biomedcentral.com/submissions 